\title{
Synthesis of Policies Applied in the Fight Against Malaria in two African Countries at different Stages of Intervention (Model of Burkina Faso and Model of Senegal) using Data from Surveys and Literature
}

Elvire MFUENI BIKUNDI ( $\nabla$ elviram5@yahoo.fr)

Université Libre de Bruxelles (ULB)

Annie ROBERT

Université Catholique de Louvain

Catherine BOULAND

Université Libre de Bruxelles (ULB)

Edouard AKOTIONGA

Ministère De La Santé

MAREME Ndèye SOUGOU

Cheikh Anta Diop University

Yves COPPIETERS

Université Libre de Bruxelles (ULB)

\section{Research Article}

Keywords: Malaria, National malaria programs, health policies, linear regression

Posted Date: May 26th, 2021

DOl: https://doi.org/10.21203/rs.3.rs-523510/v1

License: (1) This work is licensed under a Creative Commons Attribution 4.0 International License. Read Full License 


\section{Abstract}

Background: Malaria is a global public health problem with many cases each year (228 million cases in 2018 with 405,000 deaths). Most malaria cases occur in Africa.

Methods: Data used for analysis are from Demographics and Health Surveys (DHS) 2017-2018 for Burkina Faso and DHS 2017 for Senegal. We added information from a synthesis of literature. Linear regression models were performed with an estimation of the mean number of persons using ITNs among groups (urban or rural areas, wealth level, highest education level in the household and age of household head) in each country. We evaluated the importance of co-factors in the relationship between the number of ITNs (insecticide-treated nets) in a household and the number of household members by calculating the R-squared.

A criteria grid used for this synthesis of literature included eight important sub-groups: funding sources, entomological monitoring, use of ITNs, use of insecticide, malaria case management, health system organization, communication and surveillance.

Results: Senegal and Burkina Faso have the same proportion (51\%) of households in which all children under 5 sleep under ITNs. We found R-squared ( $R^{2}=0.007$ in Burkina Faso and $R^{2}=0.16$ in Senegal) for the relationship between the number of ITNs in a household and household size. When wealth level, age of head of household, area of residence (rural or urban), highest education level in the household and number of bedrooms in the household were controlled for, we found $R^{2}=0.106$ for Burkina Faso and $R^{2}=0.167$ for Senegal.

We found that Senegal's national malaria program is decentralized with entomological monitoring in all districts, which is normal considering the intervention stage in the fight against malaria. In Burkina Faso, we found centralization of routine data.

Conclusion: Our study synthesized the health policies applied in African countries which are at different stages of intervention in the fight against malaria and which have succeeded in maintaining low malaria prevalence (in Senegal) or in rapidly decreasing the prevalence of the disease (in Burkina Faso). Being close to elimination, Senegal required more active malaria surveillance than passive surveillance. Burkina Faso did not require a lot of active surveillance being not close to malaria elimination. These results merit a review in the context of each African country.

\section{Background}

Malaria is a global public health problem with many cases each year in the world (228 million cases in 2018 with 405,000 deaths). Most malaria cases occur in Sub-Saharan African countries (93\%). The prevalence of malaria in some Sub-Saharan African countries is very high. While almost all African countries have set up a national program to fight malaria with grants from international organizations, local governments, and private funds, they have not made the same progress or used the same methods in the elimination of malaria, producing tailored intervention by countries. [1, 2]

Senegal and Burkina Faso are two West African countries which each have a gross domestic products (GDP) of around 20 billion United States Dollars. They are at different stages of intervention in the fight against malaria. Senegal is close to malaria elimination while Burkina Faso is not. The national malaria programs of both countries have been very successful in recent years. Senegal has maintained low malaria prevalence for several years and malaria case numbers in Burkina Faso have decreased rapidly [3, 4]. There have been good results from national malaria programs implemented in the last 10 years in these two African countries, despite climate and socio-economic conditions which are linked tohigh malaria risk. Several studies have found that the risk of malaria infection is influenced by climate (such as quantity of rainfall or air temperature) and by socio-economic factors (such as the economic status or education level of a family) which can influence some behaviors such as the use of nets [5-7].

According to operational requirements for malaria elimination outlined by the World Health Organization, identifying and treating a high proportion of the population is crucial for countries that are not very close to elimination. They need to rapidly decrease malaria transmission in order to implement malaria elimination programs. For countries that are close to malaria elimination, strengthening of health systems with early detection and early treatment of malaria cases is critical in achieving malaria elimination [8].

Malaria is one of the major public health problems in Africa, with most cases and mortalities occurring among African children. Health policies in the fight against malaria have been implemented in Senegal and Burkina Faso, with good results in the reduction of national malaria prevalence. Studies have shown the importance of considering parameters such as funding, malaria case management, health information systems, collection of routine data for surveillance and other specific health policies in the assessment of malaria programs [911]. The aim of our study was to provide a synthesis of successful policies applied in the fight against malaria in African countries at different stages of intervention; Burkina Faso and Senegal. 


\section{Methodology \\ Data}

Using malaria diagnostic test results obtained from Demographics and Health Surveys (DHS) which are nationally representative surveys, we estimated malaria prevalence in each concerned country.

DHS data, used for quantitative analysis of ITN use, were from DHS 2017-2018 for Burkina Faso and from DHS 2017 for Senegal. We used DHS data from 2010 to 2018 to estimate longitudinal progress concerning malaria prevalence in Burkina Faso and Senegal [2].

DHS surveys also collect socio-economic data, which we used in this study: urban or rural residence, economic level of the household, possession and use of an ITN (insecticide-treated net), highest education level in the household, age of head of household, number of rooms in the house and number of household members.

During DHS surveys, a person infected with malaria was determined by several methods such as microscopy or RDT (rapid diagnostic test). For microscopy, blood smears were dried, fixed with methanol and packed. For RDT, immediate diagnostic results were determined during the survey and positive cases received drugs considered to be first-line treatment in the country. Results from microscopy testing were used for the present study [12].

We added information from a synthesis of official literature. Literature used were from the health ministries of each country and from international authorities and agencies. We used methods proposed by Judith Green and Nicki Thorogood. The synthesis of the literature was conducted according to a criteria grid. We selected official reports from 2010 to 2018, which accurately report national malaria programs in Senegal or in Burkina Faso [13-14]. Literature selected were WHO reports, President's Malaria Initiative reports, UNICEF (United Nation Children's Fund) reports $[1,12,15-16]$ and documents from the Ministries of Health of Senegal and Burkina Faso. The criteria grid used for this synthesis of literature on malaria programs included eight important sub-groups: funding sources, entomological monitoring, use of ITNs, use of insecticide, malaria case management, health system organization, communication and surveillance.

\section{Statistical methods}

Statistical analyses were performed using IBM SPSS version 20.0 and SAS studio. We performed a linear regression to investigate the relationship between number of ITNs and number of persons in a household, adjusted for age of household head, economic level of household, the highest education level in the household and the area of residence (rural or urban). Normality and homoscedasticity of regression models were verified by observing the shape of points, curves in plots and scatter plots of residuals. Figures representing Rsquared in each model were shown with their confidence intervals at $95 \%$.

We estimated the mean number of persons using ITNs among groups (urban or rural areas, wealth level, highest education level in the household and age of household head) and in each country using analysis of variance [17].

We evaluated the importance of socio-economic factors in our linear regression model for the relationship between the number of ITNs in a household and the number of household members by computing the R-squared of each model. We must note that this evaluation was performed considering only areas of intermediate malaria endemicity (prevalence $5-40 \%$ ) and high endemicity (prevalence $>40 \%$ ). Areas of low malaria endemicity (malaria prevalence $<5$ ) were not considered in this estimation.

Semi-partial correlation (correlated to R-squared) provides a solid estimate of the relative importance of each predictor in a multiple regression model. Studies have demonstrated the unique contribution of each independent variable in a multiple regression model. The square of semi-correlation represents how much the R-squared value decreases in a model when a predictor is removed. We used the decrease in the $\mathrm{R}^{2}$ value when a co-variable is dropped from the model to assess the importance of a factor in the model for each country (Senegal or Burkina Faso) [18].

\section{Results}

Data from DHS surveys used are described in Table 1. We used a sample size of 6183 households for Burkina Faso and 12797 households for Senegal. 


\begin{tabular}{|c|c|c|}
\hline & Burkina Faso & Senegal \\
\hline \multicolumn{3}{|l|}{ Description of countries ${ }^{\star \star}$} \\
\hline Population (n) & $20,835,401$ & $16,209,125$ \\
\hline Area in $\mathrm{Km}^{2}$ (\% water body) & $274,400(0 \%)$ & $196,722(2.1 \%)^{\star}$ \\
\hline Density (persons/km²) & 76 & 82 \\
\hline Gross Domestic Products (USD/ persons) & 640 & 1033 \\
\hline Human Development Index & 0.402 & 0.505 \\
\hline Agriculture (\% population) & 80 & 16 \\
\hline Population below poverty line (\%) & 33 & 33 \\
\hline Gini index for income inequality & $35.3(2014)$ & $40.3(2011)$ \\
\hline \multicolumn{3}{|l|}{ Description of DHS data used } \\
\hline Year of survey & $2017-2018$ & 2017 \\
\hline Sample size (N = number of households) & 6183 & 12797 \\
\hline Proportion of urban population & $15.8 \%$ & $34.1 \%$ \\
\hline Wealth level of households ${ }^{\star \star *}$ : & $20.5 \%$ & $31.0 \%$ \\
\hline -Poorest & $22.4 \%$ & $24.7 \%$ \\
\hline -Poor & $20.5 \%$ & $22.4 \%$ \\
\hline -Middle & $20.4 \%$ & $13.1 \%$ \\
\hline -Richer & $16.2 \%$ & $8.8 \%$ \\
\hline \multicolumn{3}{|l|}{-Richest } \\
\hline Malaria prevalence & $17.0 \%$ & $0.4 \%$ \\
\hline Household where all under 5 children sleeping under ITN & $51.5 \%$ & $50.8 \%$ \\
\hline \multicolumn{3}{|l|}{ *: $530 \mathrm{~km}$ of coasts } \\
\hline \multicolumn{3}{|c|}{ **: Data from World Bank [19] and from OECD (Organisation for Economic Co-operation and Development) [20]. } \\
\hline $\begin{array}{l}\text { ***: Construction of wealth quintiles in DHS data is based } \\
\text { supply, type of vehicle, type of flooring, radio, television, re } \\
\text { sanitation facilities, or country-specific items were used to }\end{array}$ & $\begin{array}{l}\text { ousehold popul } \\
\text { c servants, own }\end{array}$ & $\begin{array}{l}\text { ormation such as water } \\
\text { agricultural land, }\end{array}$ \\
\hline
\end{tabular}

We can observe that the proportion of the poorest households in Senegal (31.0\%) is triple the proportion of the richest (8.8\%). In Burkina Faso, there is almost the same proportion of all wealth levels in the population. The proportion of urban households in Senegal (34.1\%) is double the proportion of urban households in Burkina Faso (15.8\%). During 2010, malaria prevalence was 1\% in Senegal and 65\% in Burkina Faso (Fig. 1). Burkina Faso has made significant progress in decreasing malaria prevalence at the national level (from $66 \%$ in year 2010 to $17 \%$ in year 2018).

This figure shows the longitudinal trend for malaria prevalence in these two countries (Senegal and Burkina Faso). We decided to begin our progress curve in 2010, because it is at this time that malaria diagnostic tests were first included in nationally representative surveys (DHS surveys). We can observe that malaria prevalence in Burkina Faso has decreased greatly and malaria prevalence in Senegal has remained very low for several years. 
Table 2

Comparison of ITN number used by household in Senegal and in Burkina Faso

\begin{tabular}{|c|c|c|c|c|c|c|c|c|}
\hline \multirow[b]{2}{*}{ Number of children who use ITNs in the household } & \multicolumn{4}{|c|}{ Senegal } & \multicolumn{4}{|c|}{ Burkina Faso } \\
\hline & Mean & Lower & Upper & P-value & Mean & Lower & Upper & P-value \\
\hline Mean in & 1.20 & 1.13 & 1.33 & 0.002 & 0.96 & 0.88 & 1.04 & 0.46 \\
\hline -Urban areas & 1.38 & 1.32 & 1.42 & & 0.99 & 0.95 & 1.03 & \\
\hline \multicolumn{9}{|l|}{-Rural areas } \\
\hline Mean by household economic level: & 1.22 & 1.11 & 1.33 & $<0.0001$ & 0.88 & 0.79 & 0.97 & $<0.0001$ \\
\hline -Poorest & 1.34 & 1.21 & 1.48 & & 1.09 & 1.00 & 1.18 & \\
\hline -Poor & 1.46 & 1.33 & 1.58 & & 0.93 & 0.83 & 1.03 & \\
\hline -Middle & 1.26 & 1.11 & 1.41 & & 1.09 & 0.99 & 1.19 & \\
\hline -Richer & 1.09 & 0.91 & 1.27 & & 0.97 & 0.87 & 1.07 & \\
\hline \multicolumn{9}{|l|}{-Richest } \\
\hline Highest Education level in the household: & 1.28 & 1.21 & 1.35 & 0.43 & 0.98 & 0.93 & 1.03 & 0.36 \\
\hline -No education & 1.28 & 1.15 & 1.41 & & 1.06 & 0.941 & 1.18 & \\
\hline -Primary & 1.39 & 1.22 & 1.55 & & 0.97 & 0.85 & 1.08 & \\
\hline -Secondary & 1.17 & 0.72 & 1.62 & & 0.88 & 0.43 & 1.33 & \\
\hline \multicolumn{9}{|l|}{-Higher } \\
\hline Age of head of household: & 1.14 & 0.90 & 1.39 & $<0.0001$ & 0.81 & 0.68 & 0.94 & 0.003 \\
\hline -Under 25 & 1.20 & 1.14 & 1.27 & & 1.00 & 0.96 & 0.96 & \\
\hline-25 to 50 years & 1.63 & 1.51 & 1.75 & & 1.03 & 0.90 & 0.90 & \\
\hline
\end{tabular}

As the use of ITNs is an important element in the fight against malaria [21], we compared the mean number of ITNs used in sub-groups for each country. We observed that the mean number of ITNs used is almost the same in urban and in rural households in Burkina Faso with no significant difference ( $p$-value $=0.46)$. We found also that there is no significant difference in the number of ITNs used considering the highest education level in households in both countries ( $p$-value $=0.43$ for Senegal and $p$-value $=0.36$ for Burkina Faso) $($ Table 2$)$. Wealth level is an important factor in ITN use [21]. Poor households used significantly more ITNs than the richest households in both countries (Senegal and in Burkina Faso), which is an effective policy. Studies have demonstrated that the poorest houses are at increased malaria risk due to the absence of windows with insect filters [22].

We found a positive linear relation between the number of ITNs per household and the number of members per household in both countries. In Senegal and in Burkina Faso, the number of ITNs per household increases with the household size (Fig. 2.A and 2.B). When we controlled the relationship between the number of ITNs and the number of household members with age of household head, economic level of household, place of residence (urban/ rural), highest education level in the household and number of sleeping rooms in the household, we found for Burkina Faso $\left(R^{2}=0.106\right)$ and for Senegal $\left(R^{2}=0.167\right)($ Table 3$)$.

This result indicates that in Senegal, the number of ITNs in a household increases more rapidly with the size of the household than in Burkina Faso. Senegal is close to malaria elimination; they need to do more than apply the universal distribution of ITNs. If a resurgence of the disease is to be avoided, Senegal must also organize free distribution in targeted areas and to targeted sub-groups according to surveillance data.

We observed that socio-economic and demographic factors such as age of household head, economic level of household, place of residence (urban/ rural), highest education level in the household and number of sleeping rooms in the household had almost the same effect on the possession of ITNs in Senegal, with place of residence (urban or rural) having a slightly greater effect than other factors. In Burkina Faso, the wealth level of households had a little more influence than other socio-economic factors on ITN possession. (Table 3). 
Table 3

Importance of co-factors in the relationship between the number of ITNs in a household and the number of households members

\begin{tabular}{|c|c|c|}
\hline Model & $\mathrm{R}^{2}$ of model & \\
\hline & Burkina Faso & Senegal \\
\hline Model with all variables & 0.106 & 0.167 \\
\hline Model without age of household head & 0.105 & 0.167 \\
\hline Model without wealth level of household & 0.096 & 0.166 \\
\hline Model without place of residence (Urban/ rural) & 0.105 & 0.163 \\
\hline Model without highest education level in the household & 0.104 & 0.167 \\
\hline Model without number of sleeping room in household & 0.098 & 0.165 \\
\hline
\end{tabular}

Socio-economic factors such as wealth level must be overcome by policies implemented against malaria. Several studies have noted that poor households have a greater need for the use of ITNs than the richest households [23]. It is very important to reach all categories of households for the distribution of ITNs, particularly households in targeted areas. 
Table 4

Literature synthesis $^{*}$ of policies implemented in National program against malaria of Senegal and Burkina Faso from 2010 to 2018

\begin{tabular}{|c|c|c|}
\hline \multirow{3}{*}{$\begin{array}{l}\text { Politics } \\
\text { Funding }\end{array}$} & \multicolumn{2}{|l|}{$\begin{array}{l}\text { Countries } \\
\text { Senegal Burkina Faso }\end{array}$} \\
\hline & Around $\$ 20,000,000$ of external funds per year. & Around $\$ 25,000,000$ of external funds per year. \\
\hline & $\begin{array}{l}\text { Funders: US National Institute of Health, UK } \\
\text { Department for International Development, } \\
\text { European Commission, Wellcomtrust, Bill and } \\
\text { Melinda Gates Foundation, France, others. }\end{array}$ & $\begin{array}{l}\text { Funders: US National Institute of Health, UK Department for } \\
\text { International Development, European Commission, } \\
\text { Wellcomtrust, Bill and Melinda Gates Foundation, others. }\end{array}$ \\
\hline $\begin{array}{l}\text { Entomological } \\
\text { Monitoring }\end{array}$ & $\begin{array}{l}\text { In each district during rainy season research on: } \\
\text { resistance testing, species composition, feeding } \\
\text { preferences, sporozoite rates. }\end{array}$ & In some districts: annual entomological monitoring. \\
\hline $\begin{array}{l}\text { Use of ITNs } \\
\text { 1. Mass } \\
\text { distribution } \\
\text { 2. Routine } \\
\text { distribution }\end{array}$ & $\begin{array}{l}\text {-Free distribution of } 1.8 \text { per person every three } \\
\text { years. } \\
\text {-For pregnant women, free distribution of ITNs } \\
\text { (from first antenatal consultation). } \\
\text {-For children, free distribution once a year (in } \\
\text { targeted regions). }\end{array}$ & $\begin{array}{l}\text {-Free distribution of } 1.8 \text { per person every three years. } \\
\text {-For pregnant women, free distribution of ITNs (not always to } \\
\text { all pregnant woman. } \\
\text {-Free distribution of ITN during immunization program. }\end{array}$ \\
\hline $\begin{array}{l}\text { Insecticide use } \\
\text { 1. Indoor } \\
\text { residual } \\
\text { spraying } \\
\text { 2. Insecticide } \\
\text { resistance } \\
\text { management }\end{array}$ & $\begin{array}{l}\text { Indoor residual spraying in a whole district where } \\
\text { malaria incidence is more than } 50 \text { per } 1,000 \\
\text { persons and where indoor biting is most common. } \\
\text { Studies have been performed on the acceptability } \\
\text { of this procedure. This is an acceptable } \\
\text { intervention that has been proven to work. } \\
\text { Resistance tests were performed for several } \\
\text { insecticides in different districts. }\end{array}$ & $\begin{array}{l}\text { Policy not yet implemented. } \\
\text { Resistance tests were performed for insecticides in some } \\
\text { districts. } \\
\text { Insecticide resistance studies have been done in Burkina Faso } \\
\text { and this has enabled the malaria program to order the new } \\
\text { generation mosquito nets for the distribution campaign that } \\
\text { took place in } 2019 \text {. }\end{array}$ \\
\hline \multirow[t]{5}{*}{$\begin{array}{l}\text { Malaria cases } \\
\text { management } \\
\text { 1. Diagnosis } \\
\text { 2. Treatment }\end{array}$} & \multirow{2}{*}{$\begin{array}{l}\text {-In high transmission areas, once a week during } \\
\text { rainy season, health workers experiencing fever } \\
\text { took a home-based test. Treatment was provided } \\
\text { to positive cases. This also applied to children } \\
\text { under the age of } 5 \text { years. } \\
\text {-In areas with less than } 5 \text { cases per } 1,000 \text { persons, } \\
\text { investigations in patient's household. }\end{array}$} & $\begin{array}{l}\text {-RDT is used for almost all malaria diagnostic testing. } \\
\text { Microscopy is used to confirm malaria cases (in health } \\
\text { facilities). The confirmation rate was } 77.5 \% \text { in } 2014,91.7 \% \text { in } \\
2017 \text { and } 97.6 \% \text { in } 2018 \text {. }\end{array}$ \\
\hline & & $\begin{array}{l}\text {-First line treatment is Artesunate-Amodiaquine, Artemether- } \\
\text { Lumefantrine, }\end{array}$ \\
\hline & $\begin{array}{l}\text {-First line treatment is Artesunate-Amodiaquine, } \\
\text { Artemether-Lumefantrine, Dihydroartemisinin- } \\
\text { piperaquine. }\end{array}$ & $\begin{array}{l}(10,457,752 \text { cases in } 2017 \text { and } 10,807,674 \text { cases in } 2018 \\
\text { treated with ACT, and } 281,535 \text { in } 2017 \text { and } 267,194 \text { cases in } \\
2018 \text { of treated with injectable artesunate). }\end{array}$ \\
\hline & $\begin{array}{l}\text {-Seasonal malaria chemoprevention is } \\
\text { implemented in some regions according to WHO } \\
\text { recommendations. }\end{array}$ & $\begin{array}{l}\text {-Chemoprevention during peak season with Artesunate- } \\
\text { Amodiaquine for children under five. } \\
\text {-Several training courses on malaria case management for } \\
\text { health workers. }\end{array}$ \\
\hline & $\begin{array}{l}\text {-Availability of malaria commodities because of } \\
\text { better management due to: training of health } \\
\text { workers (best prescribing) and use of drug } \\
\text { management software (SAGE) in the health } \\
\text { system information. }\end{array}$ & \\
\hline
\end{tabular}




\begin{tabular}{|c|c|c|}
\hline $\begin{array}{l}\text { Politics } \\
\text { Health system }\end{array}$ & \multicolumn{2}{|l|}{$\begin{array}{l}\text { Countries } \\
\text { Senegal Burkina Faso }\end{array}$} \\
\hline & $\begin{array}{l}\text {-Introduction of malariology course in nursing } \\
\text { training. } \\
\text {-Several training courses for managers, health } \\
\text { workers in hospitals and in laboratories: } \\
\text { performance-based financing for producing high } \\
\text { impact health budget for a specific country, } \\
\text { training on case management and diagnosis at } \\
\text { hospital and at home, quality control of drugs } \\
\text { (register of drug equivalence). This program is } \\
\text { supported by the university and the PNLP*. } \\
\text { Malaria diploma is credited by UCAD }{ }^{\star \star} \text {. } \\
\text {-Research for new intervention: research policy } \\
\text { concerning feasibility of intervention and their } \\
\text { acceptability. } \\
\text {-Conduction of integrated logistic visits in all } \\
\text { regions for delivering a detailed report. } \\
\text {-Audits are frequently performed. } \\
\text {-Decentralization of malaria program } \\
\text { implementation. }\end{array}$ & $\begin{array}{l}\text {-Yearly training courses for malaria program staff and for all } \\
\text { health workers. } \\
\text {-Elevation of Burkina Faso Malaria National Program in the } \\
\text { organigram of Ministry of Health for more efficiency and direct } \\
\text { interaction. } \\
\text {-Implementation of drug efficacy studies. } \\
\text { - The removal of barriers to geographic and financial } \\
\text { accessibility through investments and the implementation of } \\
\text { subsidy and free policies (peaks from 2016) have contributed } \\
\text { to better attendance by populations at health facilities and to } \\
\text { better notification of cases. Hence, the increase in prevalence } \\
\text { and / or incidence. However, cases of severe malaria and its } \\
\text { lethality have decreased significantly due to the fact that the } \\
\text { population has easy access to consultation and receives good } \\
\text { quality care. }\end{array}$ \\
\hline Communication & $\begin{array}{l}\text {-Mass communication: during theater, with radio } \\
\text { communication, home visits (local context is } \\
\text { considered). }\end{array}$ & $\begin{array}{l}\text {-Mass communication campaign: education of population by } \\
\text { film projection, theater, home visits. }\end{array}$ \\
\hline Surveillance & $\begin{array}{l}\text {-Annually, continuous Demographic Health survey. } \\
\text {-Centralization of all relevant malaria data from } \\
\text { health posts in each district (creation of a web- } \\
\text { platform). }\end{array}$ & $\begin{array}{l}\text {-Collection of routine data from: district health centers, surveys } \\
\text { (DHS, MIS) and data from surveillance sites. }\end{array}$ \\
\hline $\begin{array}{l}\text { PNLP*: National f } \\
\text { UCAD**: Universit } \\
\text { References for Sy }\end{array}$ & $\begin{array}{l}\text { ght program against malaria (in French). } \\
\text { Cheikh Anta Diop de Dakar (Senegal) } \\
\text { thesis of literature: }[1,12,15-16,24-36]\end{array}$ & \\
\hline
\end{tabular}

Table 4 provides a synthesis of the policies implemented against malaria in both countries. We can observe that a lot of active surveillance and control such as home-based tests and treatments has been conducted in Senegal, compared to home-based tests and treatments in Burkina Faso [8].

\section{Discussion}

The objective of our study was to synthetize policies implemented against malaria (with best results) in these two African countries (Burkina Faso and Senegal) which are at different stages of intervention). To achieve our purpose, we used DHS survey data and information from a literature synthesis.

National representative surveys which include data on diagnostic malaria tests showed that the prevalence of malaria differs greatly from one African country to another, which prevents the implementation of the same kind of health policies against malaria in these countries. Significant differences in the prevalence of malaria are found even between neighbouring countries. In the last 10 last years, national malaria prevalence in Burkina Faso has significantly decreased and malaria prevalence in Senegal has remained very low (around 1\%) for several years.

\section{Funding}

Like almost all African countries, Senegal and Burkina Faso have national malaria programs supported by international and other external funds [32-35]. Most of the funding for the fight against malaria in both countries comes from international partners such as the US National 
Institute of Health, the UK Department for International Development, the European Commission, the Wellcomtrust and the Bill and Melinda Gates Foundation.

The big question is whether those external funds are adequately distributed according to the needs of the national malaria programs in Burkina Faso and Senegal $[33,35]$. Head, who investigated malaria research funds in African countries from 1997 to 2015 , found that Burkina Faso is in the group of the highest funded African countries concerning research on malaria (more than \$ 30 million) and Senegal is in the second highest funded group of countries (\$ 5-30 million) [36].

It is crucial that the use of funds responds to the real needs of a country. A study by Barrenho demonstrated the importance of effective coordination among different donors of malaria funds if a good level of performance in relevant policies is to be achieved [37].

\section{Entomological monitoring}

Entomological research is an important part of research for implementing regional policies against malaria. In Senegal entomological monitoring is conducted several times a year in each district [22] and in Burkina Faso it is conducted once a year in some districts. This does not necessarily indicate that one country's entomological monitoring is more effective than the others. It can be a difference in strategy based on the country context and stage of intervention in the fight against malaria. Burkina Faso may have a few highly relevant sentinel sites, a system which can be as effective as covering each district. As malaria has almost been eliminated in Senegal, a lot of active surveillance and control, including vector surveillance, is necessary. It is important for Senegal to have an entomological surveillance site in each district, but it is not necessary for Burkina Faso if fewer sentinel sites can adequately cover the whole country. Studies have found that several changes occur in mosquito behavior, mosquito abundance, composition, and dominant vectors, sometimes due to policies implemented in the fight against malaria such as the use of ITNs, the use of insecticide, or chemoprevention. Entomological monitoring is an important element in the initial stages of the implementation of a malaria intervention policy and for surveillance [38].

\section{ITN policy}

Both countries have applied a policy of free distribution of ITNs (1.8 ITNs per person every 3 years) throughout the population. Senegal does more with the additional free distribution of ITNs every year in targeted districts and to targeted populations, such as children under five.

Senegal and Burkina Faso have the same proportion (51\%) of households in which all children under 5 sleep under an ITN. In Senegal there is a significant difference between the mean number of ITNs used in households in rural and urban areas, but in Burkina Faso, there is no significant difference. A study by Thwing explained that the difference between ITN numbers in urban and rural households in Senegal was due to the fact that Senegal also applied free ITN distribution to children under five. As rural households had more children under five than urban households, it was logical that there were more ITNs in rural areas than in urban areas in Senegal [39]. Several studies have demonstrated that the use of ITNs can greatly reduce malaria risk by reducing the rate of mosquito bites and density of mosquitoes [23]. Wealth level is an important factor in ITN possession in African countries [30]. We found that poor households had the highest mean number of ITN use in both Senegal and Burkina Faso. Studies have demonstrated that the poorest houses are potentially at higher malaria risk than the richest houses [31].

The possession of ITNs does not necessarily equate to the use of ITNs. The use of ITNs in a population is strongly associated with the education of the population on the prevention of malaria. Senegal and Burkina Faso have implemented communication policies appropriate for the local context and level of education. We found that in Senegal and in Burkina Faso, there is no significant difference in the use of ITNs in relation to the highest education level in the household.

\section{Insecticide use}

Resistance tests for insecticide are performed in Senegal and Burkina Faso. A policy of indoor residual spraying has not been applied in Burkina Faso, whereas Senegal has implemented indoor residual spraying in districts where the incidence of malaria is higher than 50 per 1,000 persons. Studies have demonstrated the effectiveness of indoor spraying in the fight against malaria. A study by Pluess using randomized comparison found that indoor residual spraying significantly reduces the prevalence of malaria in unstable settings [40-41]. As Senegal is close to malaria elimination, there has been a reduction of immunity in the population. The risk of a rapid resurgence is therefore highly possible if all areas are not under control. A policy of indoor spraying is an effective tool for rapidly decreasing mosquito vector capacity in targeted areas. It must be noted that the use of ITNs in both countries has also contributed to a decrease in vector capacity. 
Insecticide resistance research is being conducted in the two countries to determine which insecticide can be used against local malaria vectors. The study of insecticide resistance in the fight against malaria is very important and can influence malaria control in several ways. Resistance to insecticide may produce a gap between the entomological studies and the efficacy of epidemiological studies [24].

\section{Case management}

First line treatment is the same in the two countries, but we found a great difference between Senegal and Burkina Faso concerning the diagnosis of cases. As malaria has almost been eliminated in Senegal, more targeted case management in high transmission areas is necessary. Home-based diagnosis is performed and malaria treatment is given to positive cases by health workers with the objective of rapidly decreasing malaria transmission. Senegal introduced home-based management of malaria cases in 2008 with rapid diagnostic tests and artemisinin-based combination therapy as treatment for positive cases [42].

A study by Landier demonstrated the importance of early diagnosis and treatment in the reduction of malaria transmission. In the case of P. falciparum malaria cases, treatment within 48 hours from the onset of fever is a preventative action against malaria transmission. Without early diagnosis and treatment or with incomplete treatment of victims following bites from infected mosquitoes, gametocyte remains in those individuals for several days after clearance of asexual parasites. They remain infected and can transmit malaria [25].

\section{Health system organization}

Senegal's national malaria program is decentralized, but the opposite is the case in Burkina Faso. Decentralization allows Senegal to implement a more effective malaria program according to the context of each district, considering, for example, dominant vector species, quantity of rainfall and temperature, and the education level of the population. As a country close to eliminating malaria, Senegal must closely monitor all districts to avoid a resurgence of the disease and maintain very low transmission. A study published in 2016 demonstrated the benefits of local contextualization of policies implemented in the fight against malaria [43].

\section{Communication policy}

Local context is more widely used in communication policies for the national malaria program of Senegal and Burkina Faso. The most appropriate methods of communication for reaching a targeted population must be tailored for different regions. The culture of each region or its socio-economic conditions must be considered if best results are to be achieved from malaria programs [44]. In Senegal, research policies on the feasibility of interventions and their acceptability are integrated into the national malaria program [28-31]. Several studies converge, finding that it is better to work within a local than a national context to eliminate this significant public health problem in Africa.

\section{Surveillance}

In Senegal, a demographic and health survey with epidemiological centers for surveillance in each district is organized every year. In Burkina Faso, routine data are collected from all districts and data from surveys (questionnaires) by mobile phone. We can observe that malaria surveillance implemented in Burkina Faso is more passive than active, while in Senegal (a country close to malaria elimination), malaria surveillance is more active than passive. Active surveillance contributes to the reduction of malaria transmission and will facilitate malaria elimination. Testing and treating during active surveillance enable the identification of people who do not go to hospitals and facilitates the early detection of malaria cases, which reduces malaria transmission. A study by Singh found that active surveillance is an effective element in policies implemented for malaria elimination [45].

\section{Limitations And Merits}

Although the strength of our study was to combine information from a synthesis of the literature with quantitative data, there are some limitations. Due to the unavailability of data, the quantitative analysis only focused on the relationships between the number or use of ITNs with the number of people in a household (with socio-economic and demographic factors controlled for). It lacks, for example, additional quantitative analyses of the availability and quality of diagnostic tests, treatment and other interventions. We hope that future studies can address this limitation.

Page 10/15 


\section{Conclusion}

We synthetized health policies implemented in the national malaria programs of Senegal and Burkina Faso considering a criteria grid with policy on entomological monitoring, the use of ITNs, the use of insecticides, management of malaria cases, health system organization, communication and surveillance.

In Senegal, entomological monitoring is conducted in each district and in Burkina Faso it is conducted in some districts once a year. As malaria has almost been eliminated in Senegal, a lot of active monitoring and surveillance is necessary, such as entomological monitoring in each district or an indoor residual spraying policy, in order to rapidly and locally decrease mosquito vector capacity.

Senegal's national malaria program is decentralized and the opposite is the case in Burkina Faso. However, we found the centralization of routine data in Burkina Faso to be effective. Being close to malaria elimination and having neighboring countries with high malaria transmission areas, it is challenging for Senegal to maintain a stable low transmission level, particularly as the immunity of its population against malaria is decreasing. The health systems of countries close to malaria elimination must be strengthened by robust research, particularly on factors which have a significant impact on transmission. These countries must be able to swiftly detect an increase in malaria cases in all areas. To maintain control of this low malaria transmission, Senegal needs to conduct entomological research in all areas to determine vector capacity in each district (longevity, density and bionomics of the mosquitoes prevalent in the concerned areas) and to improve health systems. This monitoring in all areas will enable more active surveillance for malaria case management within specific local contexts $\{46\}$.

If malaria is to be eliminated, the national malaria prevalence of Burkina Faso must be reduced. The malaria program of Burkina Faso must decrease the malaria reproduction rate to a rate lower than one. Implemented health policies must rapidly reduce mosquito vector capacity and human infectivity in order to rapidly decrease the malaria reproduction rate. Mosquito capacity as a malaria vector can be reduced through IRS (which influences the daily survival rate) and the use of ITNs (which influences the daily survival rate and human biting rate). Human infectivity can be reduced through early and effective malaria treatment [46].

Data used in our study confirmed what the synthesis of the literature demonstrated. The mean number of ITNs used per household in Burkina Faso is almost the same as in Senegal. The importance of the combination of all policies applied in accordance with the local context and the stage of malaria intervention was indicated. As malaria has almost been eliminated in Senegal, more active malaria surveillance than passive was necessary. In Burkina Faso, which is not close to malaria elimination, a lot of active surveillance was not necessary to decrease malaria prevalence in the country. A study by Gachelin et al. demonstrated the importance of combining strategies with various policies against malaria to achieve a better result [47]. These two countries are examples of successfully implemented health policies in the fight against malaria which considered both local context and stage of intervention.

Our study provided a synthesis of the health policies applied in African countries at different stages of intervention in the fight against malaria, which have strongly succeeded in maintaining low malaria prevalence (in Senegal) or in rapidly reducing it (in Burkina Faso). These results merit a review in the context of each African country.

\section{Abbreviations}

1. GDPs: Gross domestic products

2. PNLP: National fight program against malaria (in French).

3. UCAD: University Cheikh Anta Diop de Dakar (Senegal)

4. ITNs: insecticide-treated net

\section{Declarations}

\section{Ethics approval and consent to participate}

Not applicable

\section{Consent for publication}

Not applicable. 


\section{Availability of data and materials}

DHS data are available on DHS Web site

https://dhsprogram.com/data/available-datasets.cfm

\section{Competing interests}

The authors declare that they have no competing interests.

\section{Funding}

Not applicable

\section{Authors' information}

YC and EM conceived. YC designed the study. EM made statistical analysis. All authors critically reviewed literature synthesis, statistical analysis and interpretation of results.

\section{Acknowledgements}

Many thanks to all co-authors who contributed greatly.

\section{References}

1. World Health Organization. World Malaria Report (2018) https://www.who.int/malaria/publications/world-malaria-report-2018/en/. Accessed 28 Dec 2019

2. Demographic and Health Survey. Surveys Data (2017-2018) https://dhsprogram.com/Data/. Accessed 15 Dec 2019

3. World Banque. Country Report (2018) https://data.worldbank.org/country. Accessed 27 Dec 2019

4. Global Climate Data (2000). https://www.worldclim.org/. Accessed 15 Dec 2019

5. Mfueni Bikundi E, Coppieters Y. Importance of risk factors associated with malaria for Sub-Saharan African children. Int J Environ Health Res. 2017 ; doi: 10.1080/09603123.2017.1359241.

6. Tusting LS, Bottomley C, Gibson H, Kleinschmidt I, Tatem AJ, Lindsay SW, Gething PW. Housing Improvements and Malaria Risk in SubSaharan Africa: A Multi-Country Analysis of Survey Data. PLoS Med. 2017; doi: 10.1371/journal.pmed.1002234.

7. Diallo A, Sié A, Sirima S, Sylla K, Ndiaye M, Bountogo M, Ouedraogo E, Tine R, Ndiaye A, Coulibaly B, Ouedraogo A, Faye B, Ba EH, Compaore G, Tiono A, Sokhna C, Yé M, Diarra A, Bahmanyar ER, De Boer M, Pirçon JY, Usuf EA. An epidemiological study to assess Plasmodium falciparum parasite prevalence and malaria control measures in Burkina Faso and Senegal. Malar J. 2017; doi: 10.1186/s12936-017-1715-1

8. World Health Organization. From malaria control to malaria elimination. (2014) https://apps.who.int/iris/bitstream/handle/10665/112485/9789241507028_eng.pdf?sequence=1 Accessed 28 Dec 2019

9. Lechthaler F, Matthys B, Lechthaler-Felber G, et al. Trends in reported malaria cases and the effects of malaria control in the Democratic Republic of the Congo. PLoS One. 2019; doi: 10.1371/journal.pone.0219853.

10. Ashton RA, Bennett A, Yukich J, Bhattarai A, Keating J, Eisele TP. Methodological Considerations for Use of Routine Health Information System Data to Evaluate Malaria Program Impact in an Era of Declining Malaria Transmission. Am J Trop Med Hyg. 2017; doi: 10.4269/ajtmh.16-0734.

11. Scott N, Hussain SA, Martin-Hughes R, et al. Maximizing the impact of malaria funding through allocative efficiency: using the right interventions in the right locations. Malar J. 2017; doi: 10.1186/s12936-017-2019-1.

12. DHS, MEASURE. Household Survey Indicators for Malaria Control. (2013) https://www.measureevaluation.org/resources/publications/ms-13-78. Accessed 15 Dec 2019

13. Judith Green and Nicki Thorogood. Qualitative Methods for Health Research. SAGE Publications Ltd 1 Oliver's Yard 55 City Road London EC1Y 1SP. 2004 
14. Aitken, Stuart, C. and Thomas Herman. UNICEF Innocenti Research Centre. 'Literature Review on Qualitative Methods and Standards for Engaging and Studying Independent Children in the Developing World', https://www.unicef.org/ (2009) Accessed 01 Mar 2020

15. President's Malaria Initiative. National Report (2018) https://www.pmi.gov/about. Accessed 03 Mar 2020

16. United Nation International Children's Emergency Fund. Country Annual reports (2010-2018) https://www.unicef.org/. Accessed 1 Feb 2020

17. McHugh ML. Multiple comparison analysis testing in ANOVA. Biochem Med (Zagreb). 2011; doi:10.11613/bm.2011.029

18. Liu J, Lou L, Li R. Variable selection for partially linear models via partial correlation. J Multivar Anal. 2018; doi:10.1016/j.jmva.2018.06.005

19. World Bank. (2020) https://data.worldbank.org/country . Accessed 1 Feb 2020

20. Organisation for Economic Co-operation and Development (2020) https://www.oecd.org/about/members-and-partners/ . Accessed 3 Feb 2020

21. Mfueni Bikundi E, Coppieters Y. Importance of risk factors associated with malaria for Sub-Saharan African children. Int J Environ Health Res. 2017; doi: 10.1080/09603123.2017.1359241..

22. Govella N J, Chaki P P, Killeen G F. Entomological surveillance of behavioural resilience and resistance in residual malaria vector populations. Malar J. 2013 doi: 10.1186/1475-2875-12-124.

23. Wanzirah H, Tusting LS, Arinaitwe E, Katureebe A, Maxwell K, Rek J, Bottomley C, Staedke SG, Kamya M, Dorsey G, Lindsay SW. Mind the gap: house structure and the risk of malaria in Uganda. PLoS One. 2015; doi: 10.1371/journal.pone.0117396.

24. Snyman K, Mwangwa F, Bigira V, Kapisi J, Clark TD, Osterbauer B, Greenhouse B, Sturrock H, Gosling R, Liu J, Dorsey G. Poor housing construction associated with increased malaria incidence in a cohort of young Ugandan children. Am J Trop Med Hyg. 2015; doi: 10.4269/ajtmh.14-0828.

25. Landier J, Parker D M, Thu A M et al.The role of early detection and treatment in malaria elimination. Malar J. 2016: doi:10.1186/s12936-016-1399-y

26. Kleinschmidt I, Bradley J, Knox TB, Mnzava AP, Kafy HT, Mbogo C, Ismail BA, Bigoga JD, Adechoubou A, Raghavendra K, Cook J, Malik EM, Nkuni ZJ, Macdonald M, Bayoh N, Ochomo E, Fondjo E, Awono-Ambene HP, Etang J, Akogbeto M, Bhatt RM, Chourasia MK, Swain DK, Kinyari T, Subramaniam K, Massougbodji A, Okê-Sopoh M, Ogouyemi-Hounto A, Kouambeng C, Abdin MS, West P, Elmardi K, Cornelie S, Corbel V, Valecha N, Mathenge E, Kamau L, Lines J, Donnelly MJ. Implications of insecticide resistance for malaria vector control with long-lasting insecticidal nets: a WHO-coordinated, prospective, international, observational cohort study. Lancet Infect Dis. 2018; doi: 10.1016/S1473-3099(18)30172-5.

27. Ministère de la santé du Senegal. Plan stratégique national de lutte contre le Paludisme 2016-2020). http://www.pnlp.sn/wpcontent/uploads/2016/08/PNLP_PSN_VFF_03-02-2016.pdf. Accessed 7 Feb 2020

28. Sy, O., Cisse, B., Tairou, F. et al. Étude de l'acceptabilité de l'aspersion intradomiciliaire d'insecticide à effet rémanent dans le centreouest du Sénégal. Soc. Pathol. Exot. 2015; doi.org/10.1007/s13149-015-0431-8

29. Cissé B, Ba EH, Sokhna C, NDiaye JL, Gomis JF, Dial Y, et al. (2016) Effectiveness of Seasonal Malaria Chemoprevention in Children under Ten Years of Age in Senegal: A Stepped-Wedge Cluster-Randomised Trial. PLoS Med. 2016: org/10.1371/journal.pmed.1002175

30. Tine, R.C., Ndiaye, P., Ndour, C.T. et al. Acceptability by community health workers in Senegal of combining community case management of malaria and seasonal malaria chemoprevention. Malar J. 2013; doi:10.1186/1475-2875-12-467

31. Tine RC, Ndour CT, Faye B, Cairns M, Sylla K, Ndiaye MN, et al. Feasibility, safety and effectiveness of combining home based malaria management and seasonal malaria chemoprevention in children less than 10 years in Senegal: a cluster-randomised trial. Trans $\mathrm{R}$ Soc Trop Med Hyg. 2014; doi: 10.1093/trstmh/trt103.

32. Ministère de l'économie, des finances et du développement du Burkina Faso. Institut national de la statistique et de la démographie. Institut National de la Statistique et de la Démographie Burkina Faso : Enquête sur les Indicateurs du Paludisme (EIPBF) (2017-2018) http://www.insd.bf/n/contenu/enquetes_recensements/enquete_palu/EIPBF_2018.pdf. Accessed 7 Feb 2020

33. Ministère de la santé du Burkina Faso. Comptes de santé (2010-2018) https://www.sante.gov.bf/ressources/documents. Accessed 3 Feb 2020

34. Namountougou M, Simard F, Baldet T, Diabaté A, Ouédraogo JB, Martin T, Dabiré RK. Multiple insecticide resistance in Anopheles gambiae s.I. populations from Burkina Faso, West Africa. PLoS One. 2012; doi: 10.1371/journal.pone.0048412.

35. Ministère de l'économie, des finances et du développement du Burkina Faso. Institut national de la statistique et de la démographie. Annuaires de statistique du Ministère de la santé du Burkina Faso (2018) http://www.insd.bf/n/contenu/pub_periodiques/annuaires_stat/Annuaires_stat_nationaux_BF/Annuaire_Statistique_National_2018.pdf . Accessed 1 Feb 2020 
36. Head MG, Goss S, Gelister Y, Alegana V, Brown RJ, Clarke SC, Fitchett JRA, Atun R, Scott JAG, Newell ML, Padmadas SS, Tatem AGlobal funding trends for malaria research in sub-Saharan Africa: a systematic analysis. Lancet Glob Health. 2017; doi: 10.1016/S2214$109 \times(17) 30245-0$.

37. Barrenho E, Miraldo M, Shaikh M, Atun R. Vertical and horizontal equity of funding for malaria control: a global multisource funding analysis for 2006-2010. BMJ Glob Health. 2017; doi: 10.1136/bmjgh-2017-000496.

38. Gatton ML, Chitnis N, Churcher T, Donnelly MJ, Ghani AC, Godfray HC, Gould F, Hastings I, Marshall J, Ranson H, Rowland M, Shaman J, Lindsay SW. The importance of mosquito behavioural adaptations to malaria control in Africa. Evolution. 2013;doi:

10.1111/evo.12063.

39. Thwing JI, Perry RT, Townes DA, Diouf MB, Ndiaye S, Thior M. Success of Senegal's first nationwide distribution of long-lasting insecticide-treated nets to children under five - contribution toward universal coverage. Malar J. 2011 Apr 13;10:86. doi: 10.1186/14752875-10-86. PMID: 21489278; PMCID: PMC3083382.

40. Alout H, Roche B, Dabiré RK, Cohuet A. Consequences of insecticide resistance on malaria transmission. PLoS Pathog. 2017; doi:10.1371/journal.ppat.1006499

41. Pluess B, Tanser FC, Lengeler C, Sharp BL. Indoor residual spraying for preventing malaria. Cochrane Database Syst Rev. 2010; doi:10.1002/14651858.

42. Gaye S, Kibler J, Ndiaye JL, Diouf MB, Linn A, Gueye AB, Fall FB, Ndiop M, Diallo I, Cisse M, Ba M, Thwing J. Proactive community case management in Senegal 2014-2016: a case study in maximizing the impact of community case management of malaria. Malar J. 2020 Apr 25;19(1):166. doi: 10.1186/s12936-020-03238-0. PMID: 32334581; PMCID: PMC7183580.

43. Murhandarwati EE, Fuad A, Sulistyawati, Wijayanti MA, Bia MB, Widartono BS, Kuswantoro, Lobo NF, Supargiyono, Hawley WA. Change of strategy is required for malaria elimination: a case study in Purworejo District, Central Java Province, Indonesia. Malar J. 2015; doi: 10.1186/s12936-015-0828-7.

44. Essé C, Utzinger J, Tschannen AB, Raso G, Pfeiffer C, Granado S, Koudou BG, N'Goran EK, Cissé G, Girardin O, Tanner M, Obrist B. Social and cultural aspects of 'malaria' and its control in central Côte d'Ivoire. Malar J. 2008; doi: 10.1186/1475-2875-7-224.

45. Singh N, Bharti PK, Kumre NS. Active v. passive surveillance for malaria in remote tribal belt of Central India: Implications for malaria elimination. Pathog Glob Health. 2016; doi: 10.1080/20477724.2016.1223920

46. Mendis K, Rietveld A, Warsame M, Bosman A, Greenwood B, Wernsdorfer WH. From malaria control to eradication: The WHO perspective. Trop Med Int Health. 2009 Jul;14(7):802-9. doi: 10.1111/j.1365-3156.2009.02287.x. Epub 2009 May 26. PMID: 19497083.

47. Gachelin G, Garner P, Ferroni E, Verhave JP, Opinel A. Evidence and strategies for malaria prevention and control: a historical analysis. Malar J. 2018; doi: 10.1186/s12936-018-2244-2.

\section{Figures}

\section{Malaria prevalence from 2010 to 2018}

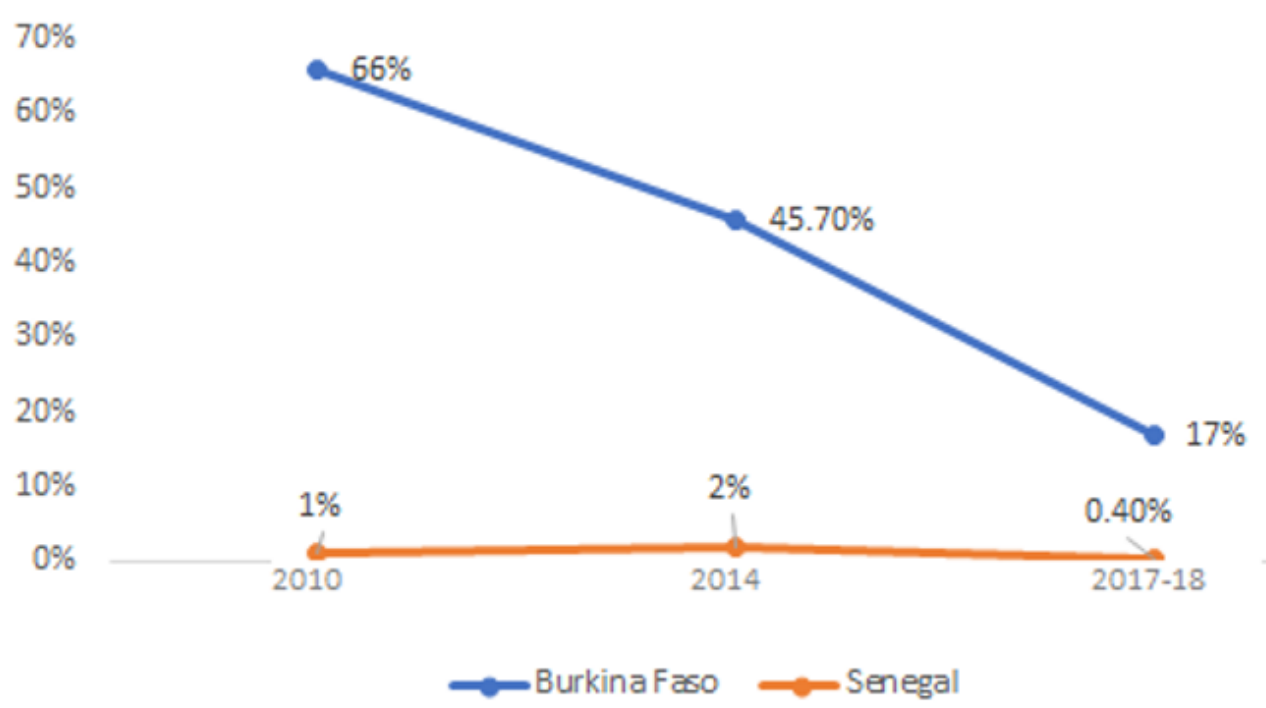

Page 14/15 
Figure 1

Progress for malaria prevalence in Senegal and Burkina Faso from 2010 to 2018
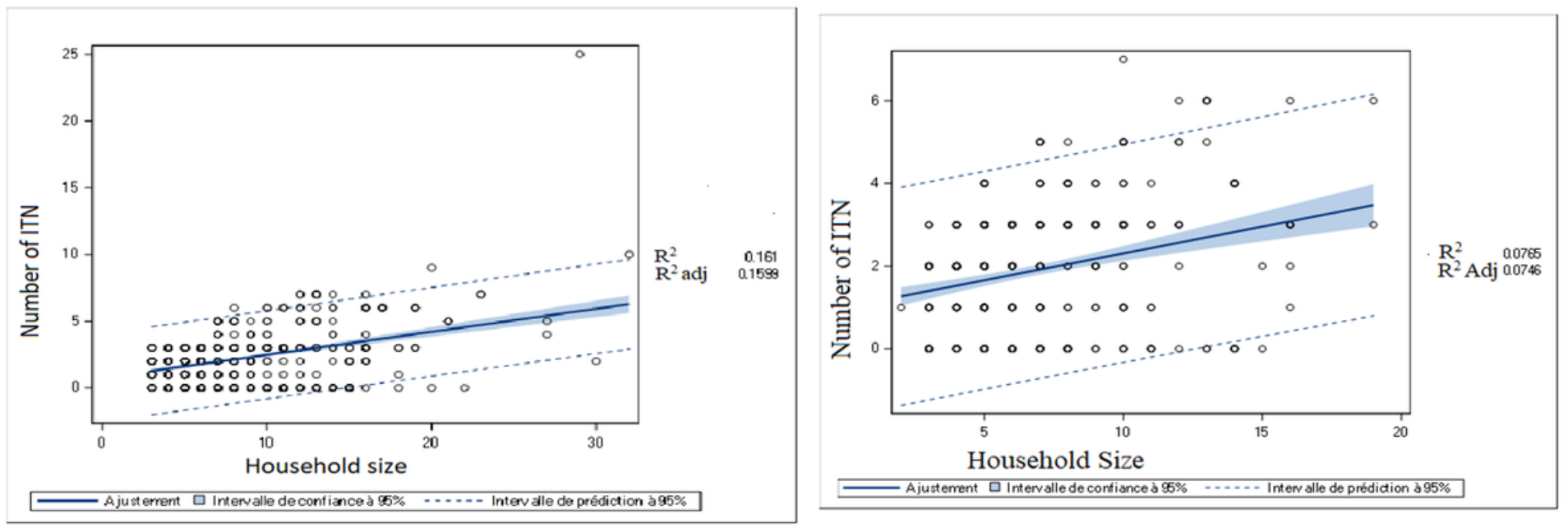

\section{Figure 2}

A. Evolution of ITN number according to number of household members in Senegal B. Evolution of ITN number according to number of household members in Burkina Faso 